\title{
Analysis on Scour Characteristics under River Bed Variation in Weir Downstream
}

\author{
Dongwoo Ko, Joongu Kang* \\ Korea Institute of Civil Engineering and Building Technology (KICT), Goyang-Si, Gyeonggi-Do, Korea \\ Email: *jgkang02@kict.re.kr
}

How to cite this paper: Ko, D. and Kang, J. (2018) Analysis on Scour Characteristics under River Bed Variation in Weir Downstream. Engineering, 10, 495-504. https://doi.org/10.4236/eng.2018.108035

Received: July 26, 2018

Accepted: August 5, 2018

Published: August 8, 2018

Copyright $\odot 2018$ by authors and Scientific Research Publishing Inc. This work is licensed under the Creative Commons Attribution International License (CC BY 4.0).

http://creativecommons.org/licenses/by/4.0/

\begin{abstract}
Various river projects are underway in small rivers in Korea that typically have natural flows. However, recent findings have shown that damages could be aggravated by structures such as weirs and drop structures during flood incidents. Experimental studies for securing the stability of flood control for these artificial structures have been insufficient, and designs applying the existing domestic design standards would not be suitable for the steep flow sections such as the actual small rivers, possibly aggravating the damages. The present study involved hydraulic model experiments conducted in a laboratory to investigate the surrounding flow patterns according to the river bed slope at the downstream part of the weir model. Further, the scour characteristics in the apron section during the overflow of the structure were analyzed to determine the appropriateness of the apron length. Thus, as the upstream river bed slope gradually increased, the experimental scour length deviated more from the design criteria formula. The results suggest that both the formula suggested by the National Construction Research Institute and Bligh's formula presented in the River Design Criteria are not suitable for steep-slope rivers, such as small rivers in Korea, because both formulas were proposed based on the seepage line distance and river bed materials without considering the slope of the river bed. Thus, in designing the apron and bed pitching of weirs and drop structures, the river bed slope, scour characteristics of weir overflow, and existing design factors should be comprehensively considered to devise a design formula appropriate for environment of the small rivers in Korea.
\end{abstract}

\section{Keywords}

Weir, Drop Structure, Hydraulic Experiment, River Bed, Scour Characteristic

\section{Introduction}

Although the functions of weirs are classified according to the purpose of an in- 
stallation, a weir is typically a structure that is installed in the cross section of a river to collect domestic water, industrial water, and water for power generation by controlling the level of the river [1]. Accordingly, weirs can maintain the normal functions of stream flows. Weirs and drop structures are not easily distinguishable owing to their similarity in shape. Nevertheless, it is common to install a drop structure in a relatively low position because the drop structure supports the river bed stabilization. Small rivers are typically located at the upstream part of the river system, and for that reason, the river width is mostly narrow, and the slope of the river bed is steep, which is vulnerable to various damages owing to the high flow energy during flood incidents. Experts have reported that artificial structures such as weirs and drop structures are the main factors that aggravate the damage from a flood, and the collapse of artificial structures as well as their neighboring levees, can lead to secondary damages.

Thus, it is crucial to investigate the causes of damage to weirs and drop structures in small rivers, and to find methods to secure their stability [2] [3]. Various methods have been proposed by researchers to reduce the damage caused by artificial structures [4]-[10]. However, there are few studies to improve the design standard by comparing with existing design standard formulas. In this respect, the present study examined the scour characteristics of a downstream weir according to change in upstream river bed slopes through hydraulic experiment using a small river weir model. Based on the test results, the aim of this study is ultimately to complement and improve the shortcomings of design standards for the length of the downstream apron for small river weirs. In this study, we investigated the characteristics of the downstream scour of the river owing to the change in the upstream slope through a hydraulic experiment. The ultimate goal of this study is to overcome the deficiencies of the design standards for downstream water basins of small rivers or streams.

\section{Hydraulic Experiment}

\subsection{Experimental Facility and Test Model}

Analytical experiments were conducted to investigate the scour characteristics according to changes in river bed slopes of a downstream weir in a straight water channel with a width of $1.0 \mathrm{~m}$ at the River Experiment Center (Andong). The specifications of the test water channel include a length of $30.0 \mathrm{~m}$, height of 1.2 $\mathrm{m}$, and maximum supply flow rate of $0.26 \mathrm{~m}^{3} / \mathrm{s}$. The $10.0-\mathrm{m}$ section at the center of this water channel is composed of a reinforced glass wall to facilitate the scour process and type observation. Figure 1 and Figure 2 show the plan view and full view of the experimental channel.

The weir model used for the scour experiment was fabricated in the laboratory as a fixed weir with breadth $(\mathrm{B}) \times$ height $(\mathrm{H})$ of $1.0 \mathrm{~m} \times 0.3 \mathrm{~m}$ in reference to the River Design Criteria (2009) published by the Ministry of Land, Transport and Maritime Affairs. Figure 3 shows the cross-section of a fixed weir presented in the River Design Criteria, as well as the weir model installed in the test water channel. 


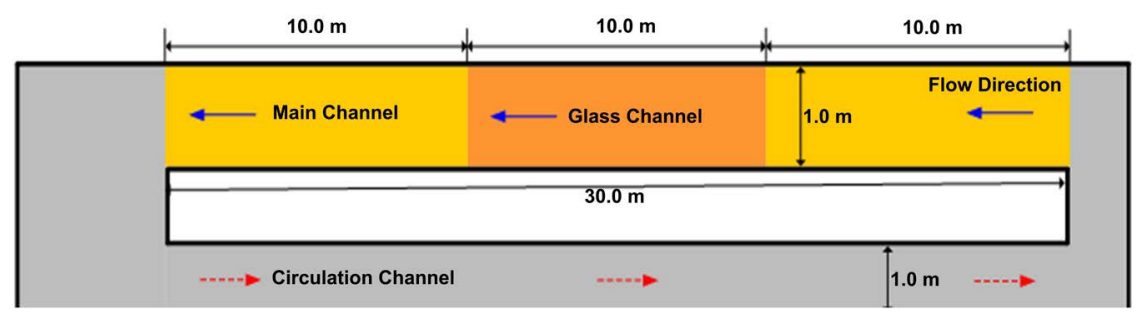

Figure 1. Plan view of experimental channel.

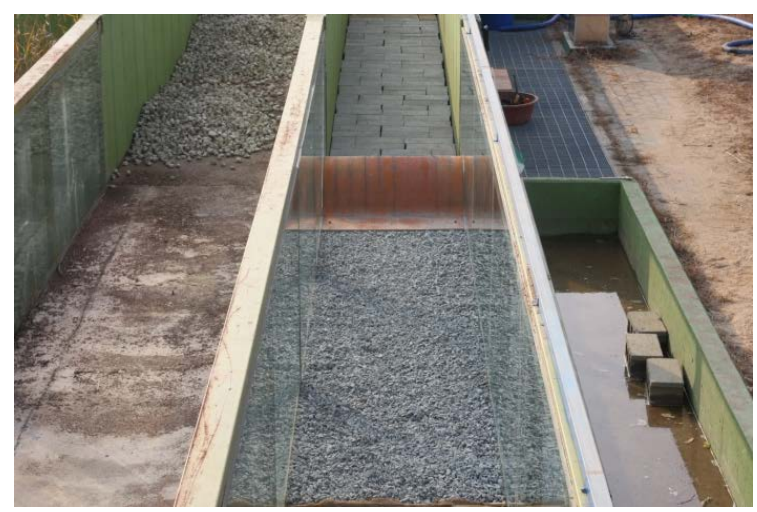

Figure 2. View of experimental site.

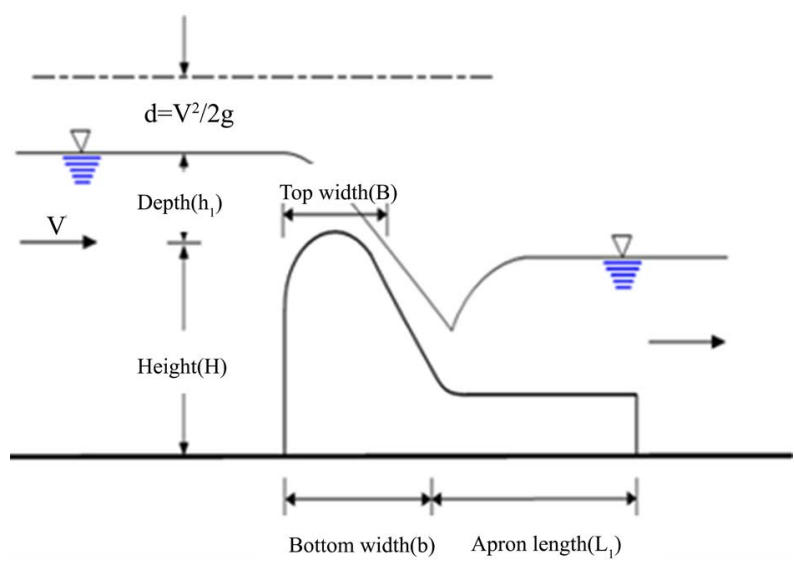

(a)

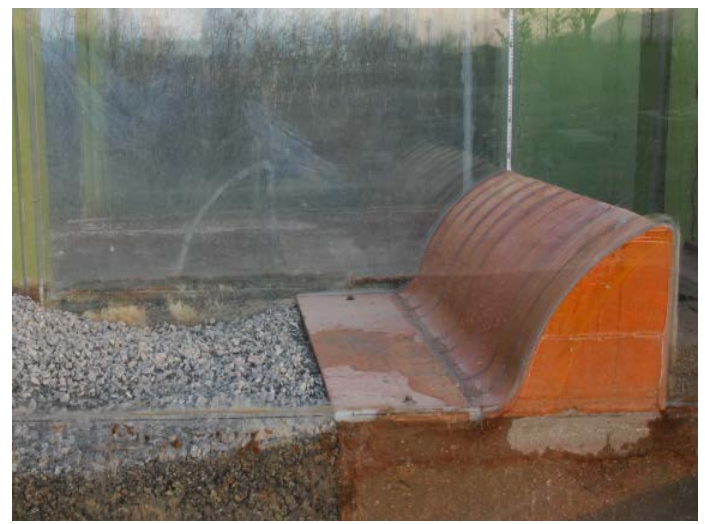

(b)

Figure 3. (a) Profile of fixed weir; (b) Installed weir model in channel. 


\subsection{Experimental Conditions and Methods}

In the hydraulic experiment, the scour characteristics of the downstream apron section of the weir were analyzed by varying the upstream river bed slopes. The flow conditions occurring at "S00" during the change in river bed slopes were selected as initial conditions. Subsequently, the scour characteristics were examined and analyzed by gradually increasing the river bed slope.

Experimental conditions were selected by assuming a total of six flow conditions according to the river bed slope, and experiments were conducted for each condition ranging from the $0 \%$ condition representing no river bed slope to $2 \%$, $3 \%, 4 \%, 7 \%$, and $10 \%$ slope conditions at the upstream part of the weir. Figure 4 shows the experimental conditions. " $\mathrm{S}$ " refers to the channel slope, and " 00 " refers to the riverbed slope. Thus, "S00" means a condition having a river bed slope of $0 \%$.

Unlike the flow that occurs in the upstream direction, the overflow at the weir

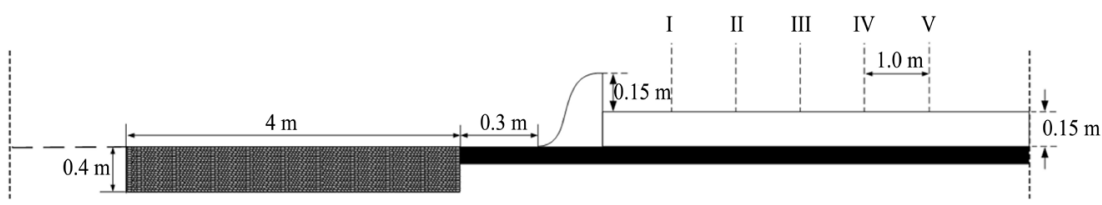

(a) $\mathrm{S} 00$

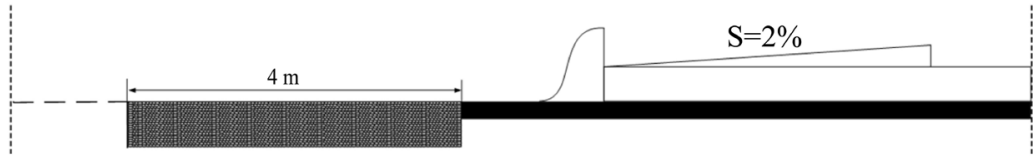

(b) $\mathrm{S} 02$

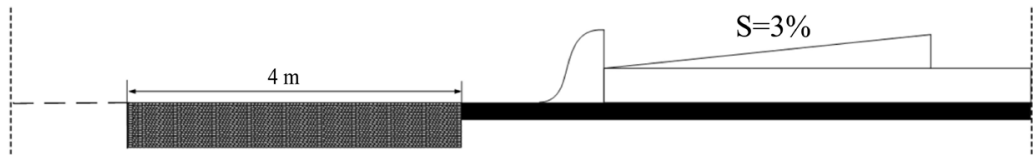

(c) $\mathrm{S} 03$

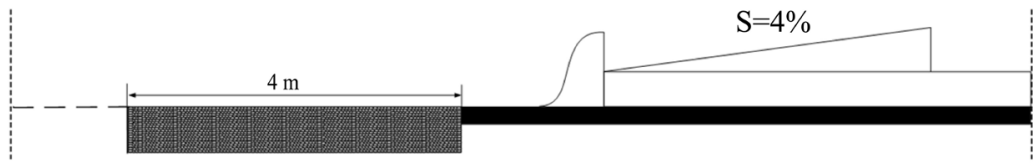

(d) $\mathrm{S} 04$

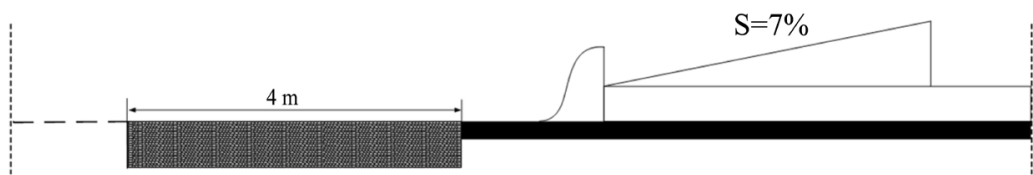

(e) $\mathrm{S} 07$

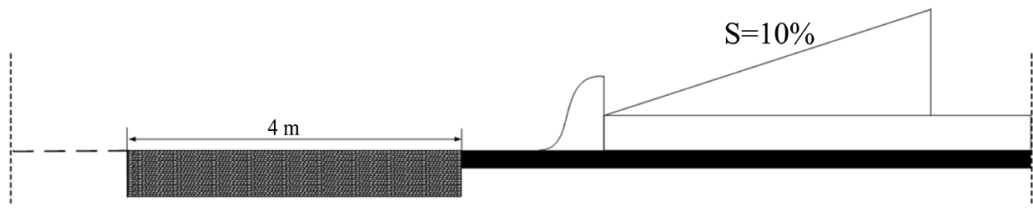

(f) $\mathrm{S} 10$

Figure 4. Experimental conditions. 
that travels in the downstream direction leads to a strong flow. For this hydraulic behavior, a laser scanner was used to compare one-dimensional scour depths and scour lengths before and after the changes in upstream river bed slopes in Figure 5. The measuring device used is a $3 \mathrm{D}$ broadband laser scanner (RIEGL LMS-Z390) with a maximum operating distance of $400 \mathrm{~m}$ and an accuracy of 6 $\mathrm{mm}$, which calculates the rectangular coordinates $(\mathrm{x}, \mathrm{y}, \mathrm{z})$ of the object by measuring the time and angle of the laser return. This laser scanner detects the reflected laser signal and calculates the distance from the reflecting object surface through the time-of-flight technique as well as the angle of the rotating mirror. The laser scanner produces and further records the vector with the object plane based on the laser scanning system. The laser scanning system emits a laser beam that can scan 800 or more points per second and detects the reflected laser to locate the three-dimensional position of the object from which the signal is reflected. Each point has the same precision when it is at the same observation distance. In other words, the RIEGL LMS-Z390 can capture 11,000 measurements per second, at distances of up to $300 \mathrm{~m}$ with a repeatability of less than 2 $\mathrm{mm}$. The unit has a 360 degree field of view, is rugged and fully portable and was designed for the rapid and accurate acquisition of $3 \mathrm{D}$ images.

The post-processing program performed filtering and matching using RIEGL's RiSCAN PRO. During filtering, the program deleted miscellaneous data such as surrounding terrain, facilities, and trees other than the object, leaving only the object data. The 3D scanning device cannot provide perfectly scanned data for the entire object through one scan. Thus, scanning was repeated several times with the proper scanning position changed. The process of matching the acquired individual data to one coordinate system was performed.

\section{Result}

\subsection{Variation in Water Surface Slope and Velocity by Changing the Bed Slope}

To investigate the flow change in the upstream section of the weir according to

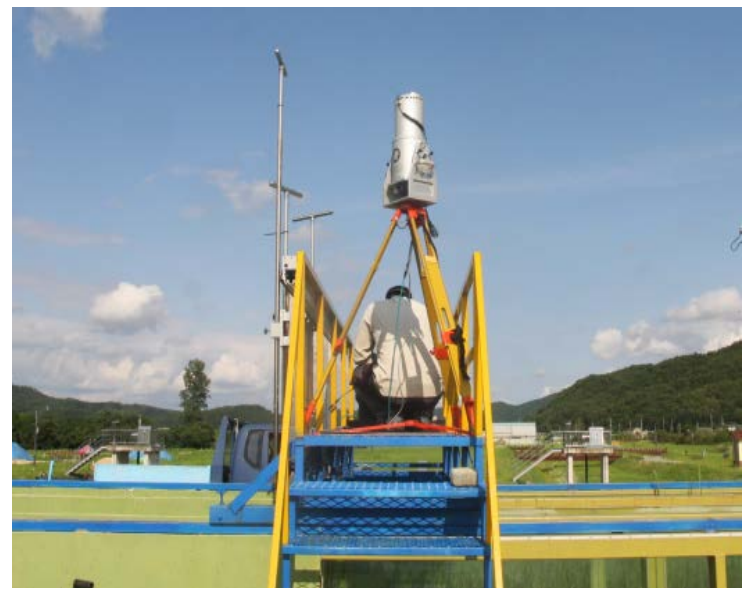

Figure 5. View of 3D laser scanner. 
the change in the river bed slopes, the experiment was conducted by assuming $2 \%, 3 \%, 4 \%, 7 \%$, and $10 \%$ conditions based on $0 \%$ condition without the river bed slope.

The water surface slope and the flow rate were measured for 18 total measuring points by three points on six sideways, up to a $5 \mathrm{~m}$ section in the upstream direction from the weir crest, and for the flow rate measurement through the one-point method, a propeller type flow meter (KENEK_VO1000) was used.

Figure 6 shows the measured data on the water surface slope and flow rate of the upstream weir according to the change in the river bed slope. When the river

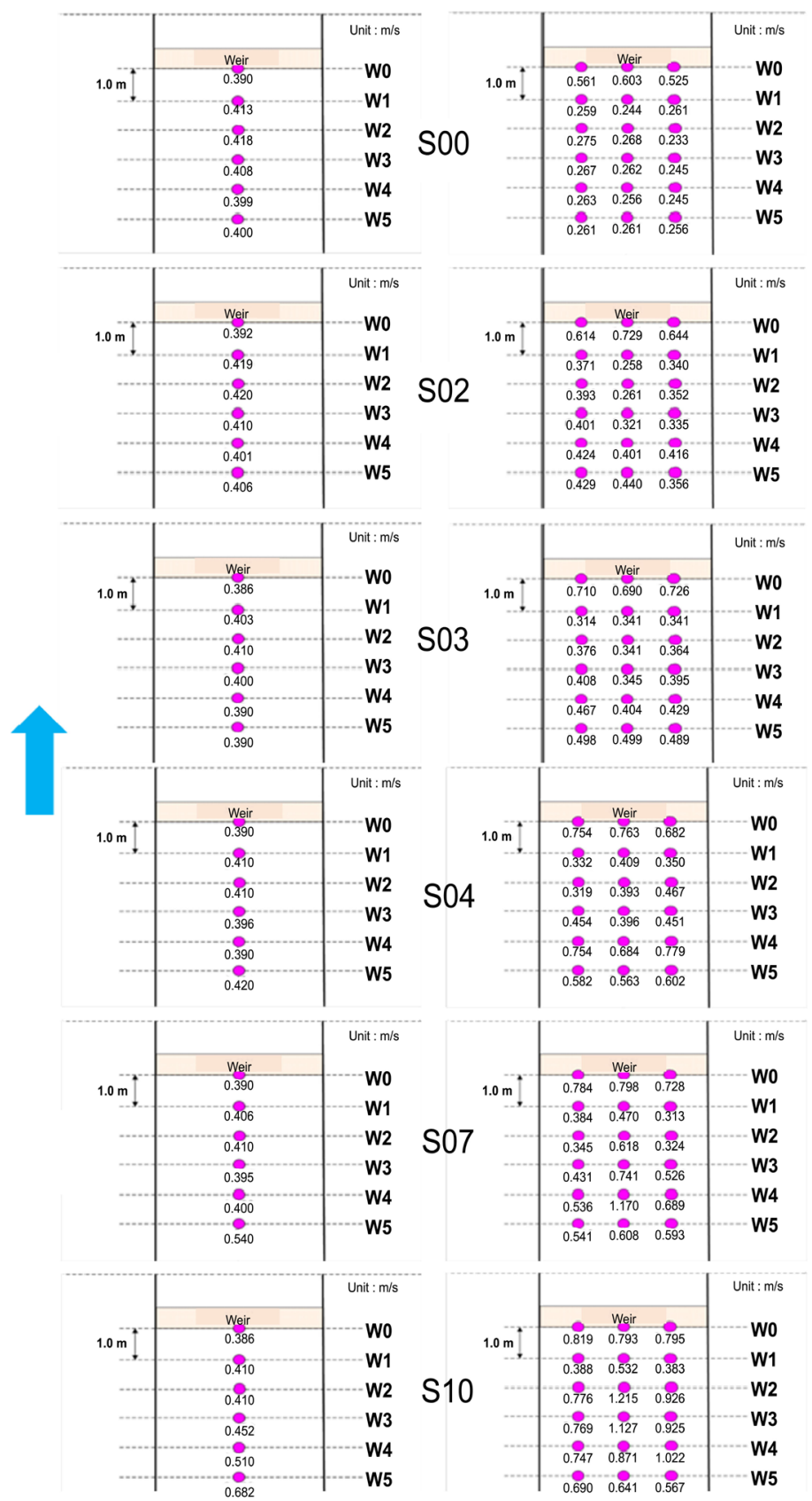

Figure 6. Variation in water surface slope and velocity under bed slopes. 
bed slope was $0 \%$, the cross-sectional reduction occurred owing to the weir model, which led to a phenomenon where the water level of the upstream part of the weir was raised while the phenomenon did not lead to a change in the flow rate.

When the river bed slope was $2 \%$ to $10 \%$, in the case of the water surface slope of the weir upstream, the cross-sectional reduction occurred because of the weir model, which led to a phenomenon where the water level of the upstream part of the weir was raised. In the case of the flow rate of the weir upstream, the decrease in the increasing flow rate was confirmed to be due to the raised water of the upstream part of the weir.

\subsection{Analysis of Scouring Effect by Changing the Bed Slope}

Analytic experiments on the downstream scour characteristics of the weir on the downstream river bed were conducted by selecting the river bed slopes as $0 \%$, $2 \%, 3 \%, 4 \%, 7 \%$, and $10 \%$ as in the analyses on the flow characteristics of the upstream part.

The local scour and sedimentation trends were analyzed at the apron downstream part according to the change in river bed slopes of the upstream part. The height of the weir and the length of the apron basin were set as $0.3 \mathrm{~m}$, and the flow rate per experiment unit breadth was 0.117 , which were equally applied to all cases. To analyze the local scour effects at the downstream part of the weir, the sedimentation was measured using the broadband laser scanner (RIEGL LMS-Z390) previously described in Figure 7.

According to the results of the analysis on the scour characteristics at the downstream part according to the change in the river bed slopes of the upstream part of the weir, it was found that the values of the scour length and scour depth change drastically as the river bed slope of the upstream part becomes steeper in Table 1 . The total energy of the water flow changed suddenly according to the changes in the river bed slope of the upstream part of the weir as the slope changed. This phenomenon occurred due to the increase in the tractive force at the downstream part of the weir.

\subsection{Comparison of Experimental and Design Formula Values}

The present study compared and analyzed the scour length measured in this
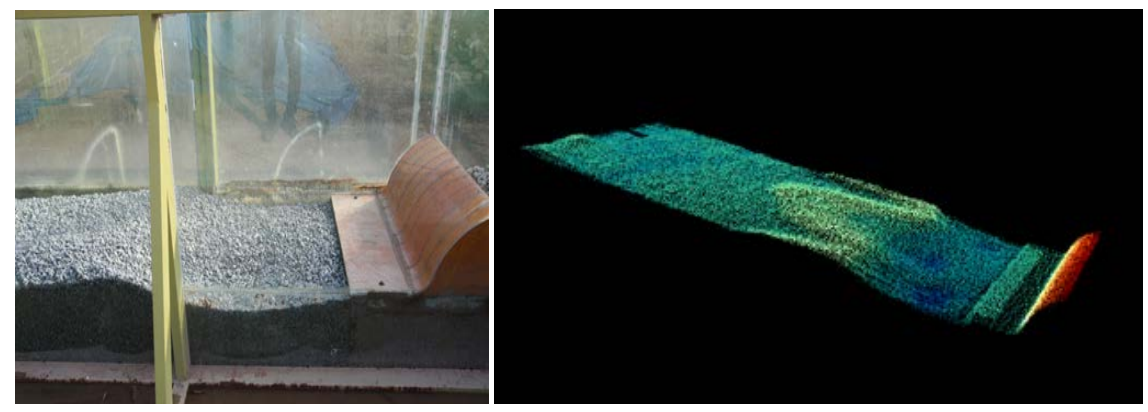

Figure 7. Results of 3D laser scanner. 
Table 1. Scouring effect by changing the bed slope.

\begin{tabular}{ccccc}
\hline $\begin{array}{c}\text { Bed slope } \\
(\%)\end{array}$ & $\begin{array}{c}\text { Max. scouring } \\
\text { depth }(\mathrm{m})\end{array}$ & $\begin{array}{c}\text { Scouring length } \\
(\mathrm{m})\end{array}$ & $\begin{array}{c}\text { Scouring } \\
\text { volume }\left(\mathrm{m}^{3}\right)\end{array}$ & $\begin{array}{c}\text { Max. deposition } \\
\text { height }(\mathrm{m})\end{array}$ \\
\hline 0 & 0.097 & 2.004 & 0.084 & 0.061 \\
2 & 0.105 & 2.371 & 0.107 & 0.078 \\
3 & 0.111 & 2.379 & 0.114 & 0.105 \\
4 & 0.116 & 2.407 & 0.144 & 0.086 \\
7 & 0.130 & 2.499 & 0.216 & 0.074 \\
10 & 0.164 & 2.521 & 0.218 & 0.073 \\
\hline
\end{tabular}

study, and Bligh's formula, as in (1), which is the apron design formula presented by the River Design Criteria [11], as well as the formula by the National Construction Research Institute, as in (2). In Bligh's formula [12], the Bligh coefficient $(C)$ values are differently defined according to the river bed materials. By comparison, this study set the $\mathrm{C}$ value for the boulder stones and gravel, which are river bed materials mainly found in small rivers (Boulder stones and gravel: $C=4-6$ ).

$$
\begin{gathered}
L_{1}=0.6 C \sqrt{H} \\
L_{1}=4.05 H^{0.316} q^{0.514} D_{50}{ }^{-0.325}
\end{gathered}
$$

where $L_{1}$ is the apron length, $C$ is the Bligh's coefficient, $H$ is the height of a weir from the apron $(\mathrm{m}), q$ is the discharge per unit $\left(\mathrm{m}^{3} / \mathrm{sec} / \mathrm{m}\right), D_{50}$ is $50 \%$ diameter of soil particle.

According to the comparative results with the formulas in the River Design Criteria, it can be seen that both the formula by the National Construction Research Institute and Bligh's formula were distributed within the permissible level when the upstream river bed slope is $0 \%$. However, as the upstream river bed slope gradually increased, the experimental scour length deviated considerably from the design criteria formula. In addition, the results obtained from the Bligh's formula are constant under various bed slopes in Table 2. The results suggest that both the formula by the National Construction Research Institute and Bligh's formula presented in the River Design Criteria are not suitable for steep-slope rivers, such as small rivers in Korea, because both formulas were proposed based on seepage line distances and river bed materials without considering the slopes of the river bed. Thus, in designing the apron and bed pitching of weirs and drop structures, the river bed slope, energy gradient, and flow characteristics of weir overflowing as well as the existing design factors should be considered to devise a design formula appropriate for environment of the small rivers in Korea.

\section{Conclusions}

In the present study, hydraulic model experiments were conducted in the River Experiment Center (Andong) to analyze the flow characteristics of the weir 
Table 2. Comparison of experimental and design formula values.

\begin{tabular}{ccccc}
\hline $\begin{array}{c}\text { Bed slope } \\
(\%)\end{array}$ & NCRI & $\begin{array}{c}\text { Bligh's formula } \\
L_{1}(\mathrm{~m})\end{array}$ & $\begin{array}{c}\text { Bligh's formula } \\
L_{1}(\mathrm{~m})(C=4)\end{array}$ & $\begin{array}{c}\text { Experimental values } \\
L_{1}(\mathrm{~m})(C=6)\end{array}$ \\
\hline 0 & 2.59 & 1.97 & 2.46 & $S_{L}(\mathrm{~m})$ \\
2 & 2.59 & 1.97 & 2.46 & 2.304 \\
3 & 2.59 & 1.97 & 2.46 & 2.671 \\
4 & 2.59 & 1.97 & 2.46 & 2.679 \\
7 & 2.59 & 1.97 & 2.46 & 2.707 \\
10 & 2.59 & 1.97 & 2.46 & 2.799 \\
\hline
\end{tabular}

downstream part according to the change in river bed slopes as well as the scour characteristics in the downstream part of the apron. This ultimate aim of this study is to secure the flood control stability of artificial structures such as weirs and drop structures, and further minimize the casualties and disaster damage due to the collapse of the structures. The results of the weir model scour impact analysis through this experiment are as follows.

The results showed that the values of the scour length and scour depth changed significantly as the river bed slope at the upstream part became steeper. The total energy gradient of the stream flow rapidly changed with the change in the river bed slope, and thus, the rapid change occurred due to the increase in the tractive force of the weir downstream part.

This study analyzed the scour length measured through these experiments and compared its findings with both the formula by the National Construction Research Institute and Bligh's formula presented in the River Design Criteria. In this study, the range of the $C$ value was set for the amphibole and gravel, which are mainly bedrock materials in the small river stream (Cave and Cobble: $C=4$ 6). In Bligh's formula, the Bligh coefficient $(C$ ) values are differently defined according to the river bed materials. By comparison, this study set the $C$ value for the boulder stones and gravel, which are river bed materials mainly distributed in the small rivers (Boulder stones and gravel: $C=4-6$ ).

According to the comparative results between experimental values and existing design standard formulas, it can be seen that both the formula by the National Construction Research Institute and Bligh's formula are distributed within the allowable threshold when the upstream river bed slope is $0 \%$. However, as the upstream river bed slope gradually increased, the experimental scour length deviated considerably from the design criteria formula. The results suggest that both the formula by the National Construction Research Institute and Bligh's formula presented in the River Design Criteria are not suitable for steep-slope rivers such as small rivers in Korea because both formulas were proposed based on the seepage line distance and river bed materials without considering the slope of the river bed. Thus, in designing the apron and bed pitching of weirs and drop structures, the river bed slope, energy gradient, and flow characteristics of the weir overflow (approaching velocity and Froude number), and existing design factors should be comprehensively considered to devise a design formula 
appropriate for environments of small rivers in Korea.

\section{Acknowledgements}

This research described in this paper was financially supported by "Study on Depth Criteria of City Gas Pipeline buried in River" from Korea Gas Safety Corporation.

\section{Conflicts of Interest}

The authors declare no conflicts of interest regarding the publication of this paper.

\section{References}

[1] Guan, D., Melville, B.W. and Friedrich, H. (2015) Live-Bed Scour at Submerged Weirs. Journal of Hydraulic Engineering, 141, 887-890. https://doi.org/10.1061/(ASCE)HY.1943-7900.0000954

[2] Lee, S.J. and Yoon, K.S. (2005) Safety Evaluation of Revetment around Barriers and Drop Structures. Korean Society of Civil Engineers, 887-890.

[3] Lee, S.J., Yoon, K.S. and Hwangbo, J.G. (2006) Design of Revetment around Barriers and Drop Structures. Korean Society of Civil Engineers, 331-334.

[4] Gaudio, R., Marion, A. and Bovolin, V. (2000) Morphological Effects of Bed Sills in Degrading Rivers. Journal of Hydraulic Research, 38, 89-96. https://doi.org/10.1080/00221680009498344

[5] Lenzi, M.A., Marion, A., Comiti, F. and Gaudio, R. (2002) Local Scouring in Low and High Gradient Streams at Bed Sills. Journal of Hydraulic Research, 40, 731-739. https://doi.org/10.1080/00221680209499919

[6] Lee, S.O., Yoon, S.E. and Song, J.W. (2011) Temporal Variation of Local Scour Depth in the Downstream of Weir with Shapes. Journal of Korean Society of Civil Engineers, 31, 353-360.

[7] Lashkarara, B., Ghotbi, S.M.H. and Armaghani, A. (2012) Managing Local Scour Downstream of Cross-River Structures Case Study: Balaroud Inverted Siphon. World Applied Sciences Journal, 20, 570-576.

[8] Helal, E.Y. (2014) Minimizing Scour Downstream of Hydraulic Structures Using Single Line of Floor Water Jets. Ain Shams Engineering Journal, 05, 17-28. https://doi.org/10.1016/j.asej.2013.06.001

[9] Ahmed, A.A.M. (2015) Physical Model Study for Mitigating Local Scour Downstream of Clear Over-Fall Weirs. Ain Shams Engineering Journal, 06, 1143-1150. https://doi.org/10.1016/j.asej.2015.03.013

[10] Shafai, B.M., Nabavi, S.M.R. and Dey, S. (2016) Scour Downstream of Grade Control Structures under the Influence of Upward Seepage. Acta Geophysica, 64, 694-710. https://doi.org/10.1515/acgeo-2016-0024

[11] KWRA (2009) Rivers Design Criteria \& Commentary. KWRA, Korea.

[12] Hussein, K.B., Dardier, M.A., Seif, A.K. and Elsheemy, A.A. (2017) Studying Effect Inclination of Cutoff on the Percolation Length under Aprons of Hydraulic Structures Founded on Isotropic Soil. International Research Journal of Engineering and Technology, 04, 1208-1224. 